\title{
A Flood Forecasting Model based on Wireless Sensor and Actor Networks
}

\author{
Sheikh Tahir Bakhsh ${ }^{1}$, Mohammed Basheri ${ }^{4}$ \\ Information Technology Department \\ King Abdulaziz University \\ Jeddah, Saudi Arabia
}

\author{
Naveed Ahmed ${ }^{2}$, Basit Shahzad ${ }^{3}$ \\ Faculty of Engineering and Computer Sciences \\ National University of Modern Languages \\ Islamabad, Pakistan
}

\begin{abstract}
Flood forecasting is a challenging area of research that can help to save precious lives by timely intimating about the flood possibilities. The role of advancements in computing and allied technologies has moved the research towards a new horizon. Researchers from all over the world are using Artificial Neural Networks (ANN), Global Information Systems (GIS), and Wireless Sensor Networks (WSN) based schemes for flash flood forecasting and hydrological risk analysis. ANN and GIS-based solutions are much costly whereas the analysis and prediction using WSN require much less cost for infrastructure deployment. It will enable the use of flood prediction mechanisms in the third world and poor countries. New variation in storage capacity can be a vital source to eliminate or reduce the chance of flood. By considering this observation, it is proposed to develop a generic flood prediction scheme that can manage the system as per resources and environmental conditions. A heterogeneous WSN has considered where powerful Collector Nodes (CN) continuously takes values from member sensor nodes in the region. CN transmits the alerts to Administration Unit (AU) when threshold values are crossed. It is proposed to save the threshold values from all water sources like storage capacity, water inflow, and outflow in the repository for decision making. Moreover, environmental parameters including water level, humidity, temperature, air pressure, rainfall, soil moisture, etc. are considered for the analysis of flood prediction. We have also considered the evaluation of these parameters in specified boundary values that were not considered in existing schemes. In this research study, we have used Arc GIS and NS2 simulation tools to analyze the parameters and predict the probability of the occurrence of a flood.
\end{abstract}

Keywords-Flood forecasting; GIS; remote sensing; hydrology; particle swarm optimization

\section{INTRODUCTION}

Flood forecasting is the real-time weather forecasting metrological technique used in the rainfall-runoff process leading towards the flow of water levels in the specific region of interest. Flood prediction helps the hydrologists to investigate when and where the extreme event of Flood will occur [1]. It depends on the intensity of rainfall occurred based on the rate of change in the environmental conditions. Accurate flood prediction helps scientists and researchers to understand the relationship between flood forecasting and rainfall [2]. The web-based technologies play a vital role in the prediction of floods and the management of other disasters [3]. Wireless sensor networks (WSN) consist of small low power nodes that can collectively sense the environment and transfer the desired

Deanship of Scientific Research (DSR), at King Abdulaziz University, Jeddah, under grant no. 611-153-D1439 readings to a central server. WSN provides an early flood prediction scheme, especially in underdeveloped countries. The rainfall gauges installed on the wireless sensor network also plays a vital role in calculating flood flow intensity and thrust value. Fig. 1 provides in deep detail the role of wireless sensor networks used especially in emergency circumstances [4-6]. The sensor nodes are responsible to transfer the disaster-related information (rainfall intensity including Flood water level) to the cluster head nodes. The cluster nodes exist in the middle of the multiple sensor nodes. The cluster nodes are capable to communicate with each other and to the gateway node. The gateway node is connected to the centralized global communication infrastructure.

Artificial neural networks (ANN) provide a mechanism to analyze and make a decision based on existing data records. Flood prediction schemes based on ANN are discussed under the following two categories. Particle swarm optimization schemes $[7,8]$ are based on a computational method that optimizes the complex problem which results in the improvement of a candidate solution. ANN-based fuzzy logicbased Schemes $[9,10]$ are based on the integration of neural networks and fuzzy logic. For the implementation of an Artificial neural fuzzy inference system, we can select the best parameters for flood forecasting based on genetic algorithms. Time series based data mining schemes [11] are also used in flood forecasting. It has been used to predict the continuous values of data based on historical trends. The results had been obtained based on hydro metrological data based on the successfully obtained records stored in the database. WSN and GIS technologies are also merged to provide a solution to flooding prediction techniques. A geo sensor network plays a vital role in acquiring spatial information. They can be successfully deployed in air, buildings, underwater, and on the body having onboard processing capability [12].

The research report emphasizes its focus on the implementation of direct diffusion protocol in case of flood events. The floods are one of the major events of environmental disasters. The major objective of this research is the water level monitoring during the extreme event of floods. The simulation setup in the proposed network model has been implemented by WSN configuration by using OMNET++ discreet event simulator. The scalability is an important factor in WSN which includes end to end transmission delay versus throughput. Throughput is the classification of network performance transmitted over bits per second on the selected communication channel. The simulation results in Fig. 2 had 
been obtained graphically in which the $x$-axis represents the number of wireless sensor nodes and the y-axis represents the average energy cost per sensor node [13].

Flood prediction schemes are discussed categorically to identify the level of work already done in this area of research. The review is generally based on ANN, WSN, and GIS-based schemes used in managing the flood-related risks and doing effective forecasting in the areas of disaster management. ANN is used to extract the required data either from existing datasets containing flood-related details for previous years or live data capturing form radars and sensor networks. Existing schemes are discussed in subsections and shown in Fig. 3. The network architecture for the flood forecasting system consists of a distributed prediction algorithm. The optimum intermediate deployment scheme has been used for WSN based communication infrastructure. The fuzzy risk analysis scheme is implemented employing the probability distribution method [1].

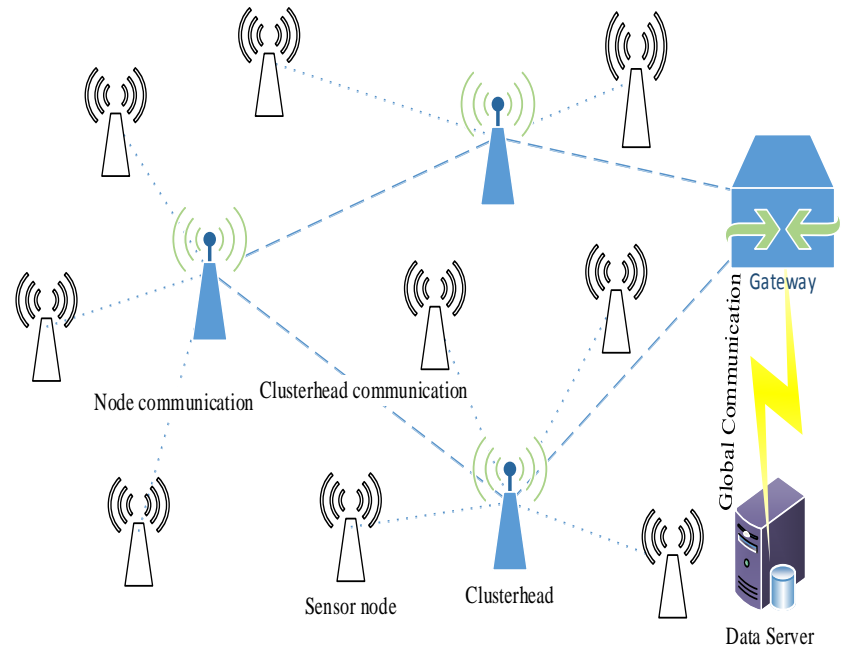

Fig. 1. A Real-Time Wireless Sensor Network used in Flood Forecasting.

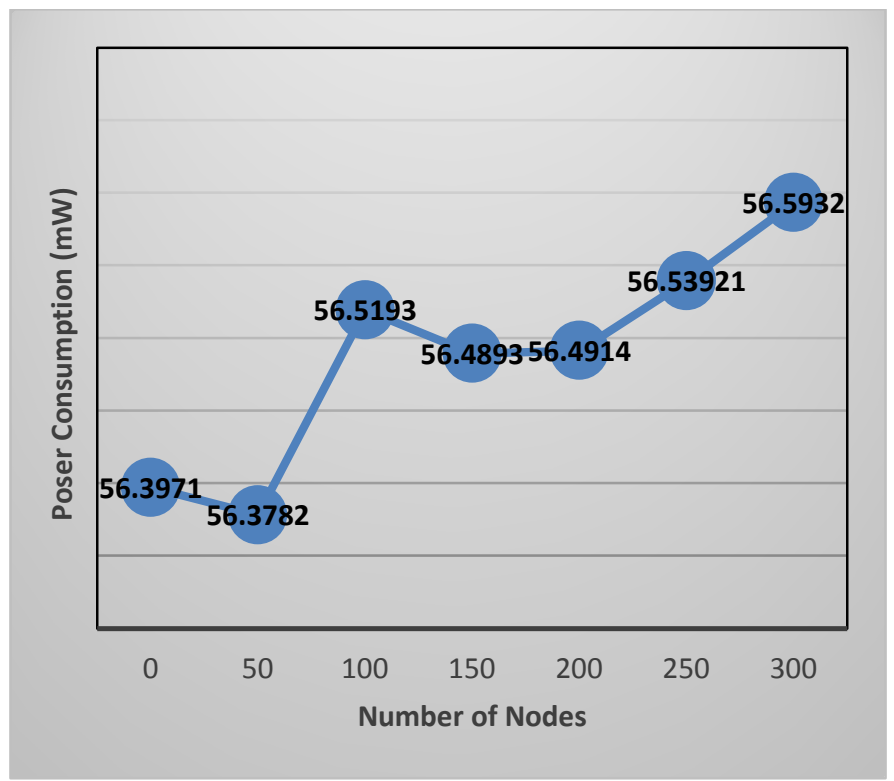

Fig. 2. Wireless Sensor Nodes Versus Power Consumption Overhead.

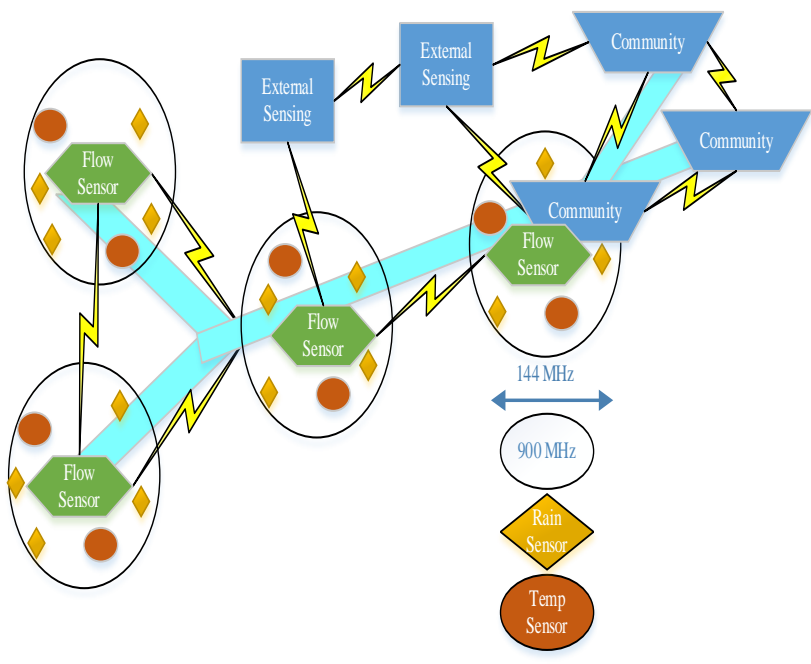

Fig. 3. Deployment of Wireless Sensor Nodes for Flood Forecasting.

The rest of the paper is organized into the following sections. Section 2 provides a literature review based on flood forecasting techniques. Section 3 provides a problem statement and research questions. Section 4 and 5 provide the proposed solution and research discussions respectively. Finally, the paper is concluded in Section 6.

\section{LITERATURE REVIEW}

The mathematical formulation of the Flood forecasting scheme is designed based on the geometrical distribution of wireless sensor nodes [14-20]. Fig. 4 explains in deep detail about the deployment scheme related to the different categories of wireless sensor nodes. The computational nodes are responsible for strong processing capability. For every two computational nodes in between the middle exists duplicate node. Duplicate node is responsible to ensure connectivity between the left and right computational node. The Intermediate nodes are responsible for transferring the river flow condition from the computational nodes to a centralized office node, the head node in this case. The researchers had also proposed the distributed prediction model based on air temperature, rainfall, and water discharge level [21].

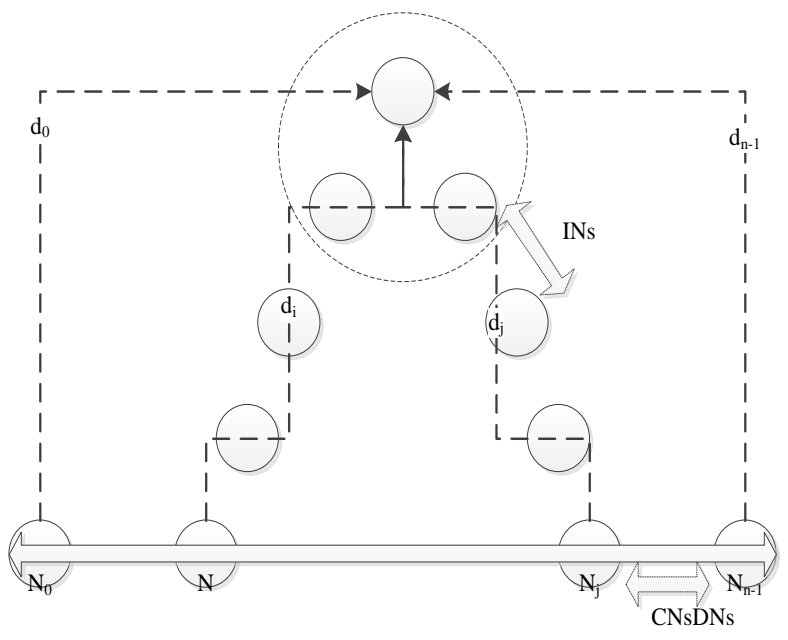

Fig. 4. Distribution of Wireless Sensor Node for the Scheme. 
The analysis of flood management is being done by using the multi-layer perception, neural network model. The parameters being used for this purpose are the velocity of water in meter per second, humidity in air measured in percentage, the rain in millimeters, the speed of wind in kilometers in each hour, and the pressure of the atmosphere is measured in its respective units. Though there are several tools for implementing the artificial neural networks (ANN) but the for clarity and simplicity the implementation of ANN is being done by using the Matlab simulation tool [10] as shown in Fig. 5. The formation of the artificial neural network model is such that it consists of three layers, the layer that deals with the inputs are called the input layer, the layer dealing with the outputs is called output layer, while the third layer that deals with the processing of the ANN are called the hidden layer. The output of the ANN model demonstrates the warning situation about the possible prediction of flood at low, high, or very high levels.

In hydrological modeling, it is very common to use particle swarm optimization technique. Particle swarm optimization is a technique based on stochastic groups and is considered to be a segment of evolutionary computing algorithms that were developed by Kennedy and Eberhart. In PSO techniques there exists a group of particles that are formed at random and are located in the positions which are already specified and move through the entire space to potentially locate the expected solution. The particles learn by themselves while living within a group by using the neural network and also work for solution identification. The emphasis of the PSO is on the effective and appropriate fitting of the particles in the space and are called as personal best (pbest) and global best (gbest) collectively depending on the speed of the movement towards the velocity of the particle in the hyperspace. PSO uses two equations [7]. The equation (1) is known as movement equation:

$\operatorname{Loc}_{\text {Present }}=\operatorname{Loc}_{\text {Previous }}+V_{i} \Delta t$

The location of the particle changes and the current position of the particle can be determined by using the past position ( $L o c_{\text {Previous }}$ ) of the particle in the described vector space along with the velocity of that specific particle in a specific time frame $\left(V_{i} \Delta t\right)$.

$V_{i}=w V_{i-1}+C_{1} * \operatorname{rand}() *($ Pbest - preslocation $)+C_{2} *$ rand ()$*($ gbest - prelocation $)$

Equation (2) records and elaborates on the change in velocity for the identified particles within the whole space of the movement known as the personal best and global best. In the previous equation $V_{i}$ is the initial velocity of the particles, $\Delta t$ is the time interval for the movement of particles with $\mathrm{n}$ a hyperspace, $V_{i-1}$ is the previous velocity, $\operatorname{random}()$ is the random number value for example $(0,1,2,3 \ldots \ldots . .$.$) and C_{1}, C_{2}$ are the acceleration of the particles within the entire space. The core of this research work is based on identifying the application of particle swarm optimization algorithm for improving the learning process.

Artificial neural networks fuzzy logic-based scheme is a multilayer feedforward and backpropagation algorithm which deals in forwarding the weighted connections from input layers towards the output layers [9]. The artificial neural network model finds a set of attributes that formulates the basis for the If-then fuzzy rules based on the relevant number functions. To maintain efficiency in mathematical modeling and optimization technique Sugneo interface system has been adopted. The $1^{\text {st }}$ order Sugeno fuzzy model can be described mathematically using the following equations. Fig. 6 demonstrates the formation of the ANFIS system which consists of the output layer as Layer 5, the input layer as Layer 1, and the hidden layer as Layers 2, 3, and 4.

Rule 1: If $X$ is $A_{1}$ and $Y$ is $B_{1}$, then $f_{1}=P_{1 x+q 1 y+r 1}$

Rule 2: If $X$ is $A_{2}$ and $Y$ is $B_{2}$, then $f_{2}=P_{2 x+q 2 y+r 2}$

The above mentioned Rule-based equations depend on the output function f corresponds to the input vector value $X$ and $Y$. The values $p, q$, and $r$ represent the constant quantities.

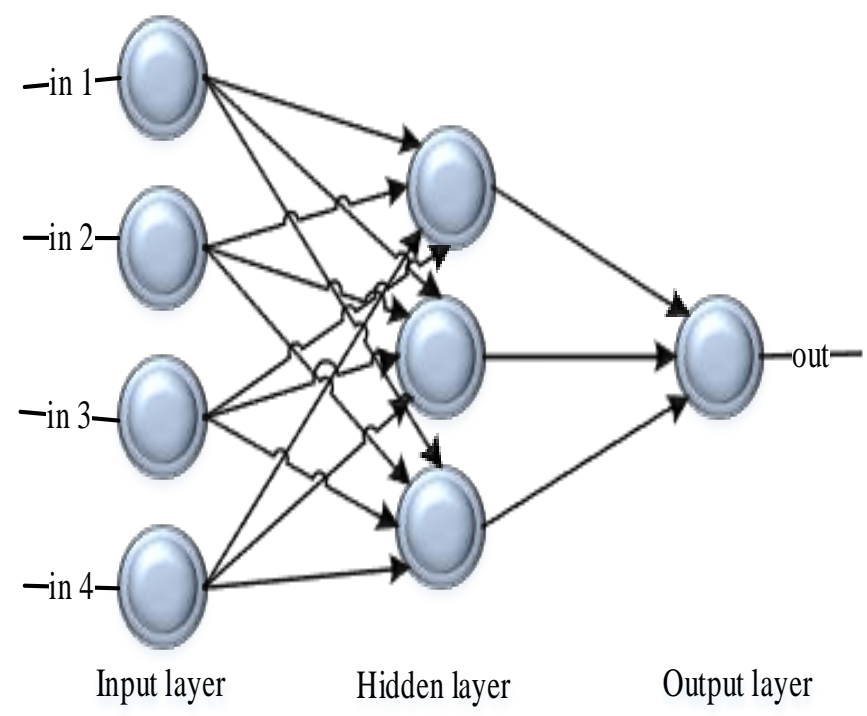

Fig. 5. Model of Artificial Neural Network for Flood Prediction.

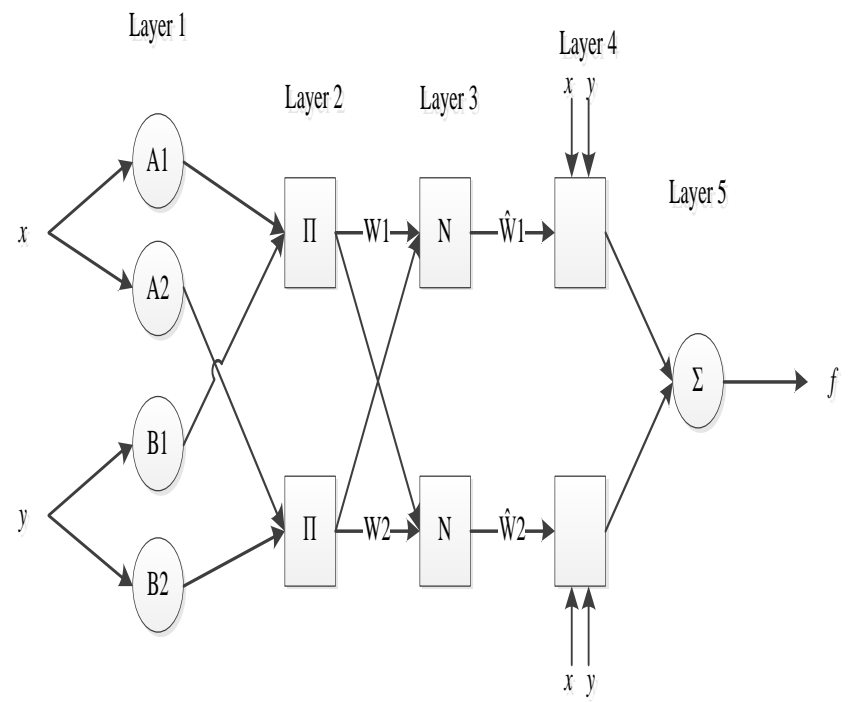

Fig. 6. Five-Layer Feed forward ANFIS System. 
The use of Ad hoc WSN is pretty common nowadays in the real-life application in the areas like telemedicine, underwater wireless sensor networks and disaster management, and vehicle Ad hoc networks. Disaster management consists of many such applications that are of direct benefit to mankind and includes floods, earthquakes, fire, hurricanes. WSN's can be seen as energy-efficient multi-hopping systems having the capability to transfer information across nodes using Ad hoc relay station [22-29]. The model that has been proposed in this paper uses web-based GIS. The prediction model takes live data from the gateway in the locality of the flood-affected area. The node on the gateway is connected to sensor nodes working on p-to-p architecture. The adaptive sampling results are based on different time events that demonstrate the working of sensors in allocated time gaps along with the intensity of variance of its signals at discrete events [31]. Fig. 7 provides detailed information about the fact that how the WSN and the GIS can be integrated and as a result, a framework for environmental modeling has been proposed and consists of the following parameters.

1) Identification and selection of the desired region on the map.

2) Application of the WSN on the map according to communication and sensing range.

3) Tabulation of data from sensors to the database.

4) Improving the database's capability to handle the increasing amount of data.

5) Deployment of the proposed framework by using the postgre SQL database.

The critical evaluation of the research study in Table I which is extracted from the literature discussed. It describes the role of GIS and WSN used in Flood forecasting along with their pros and cons. The Author [1] had discussed the Fuzzy logic based scheme for flood forecasting and disaster risk analysis. A distributed modeling technique is used for weather forecasting. The Metrological data set (COSMO) is used to calculate the rainfall peak discharge ratio for a relatively short duration [2]. The hydrological model is used to calculate flash fold events. The temporal and spatial resolution is used to calculate the rainfall-runoff process [5]. The authors [2, 5] had focused their research on using metrological models for extreme weather conditions including rainfall. ANN-based flood forecasting model has been designed based on input, output, and hidden layers [10]. According to hydrologists the real-time flood analysis and prediction are performed atkaluganga river srilinka [33].

WSN based Statistical Model is designed to predict the extreme event of floods [17]. The authors [17, 26] had proposed the WSN based scheme to forecast extreme events of flood in case of disaster circumstance. The hydrological modeling technique is used to predict floods based on numerical weather prediction [28]. The authors [28, 30] had proposed the mathematical model for flood forecasting in case of disaster circumstance. GIS-based flood forecasting Model is designed to calculate the flood series frequency [31-42]. The authors $[10,35]$ had focused their research on designing the conceptual model for flood forecasting. The regression-based flood forecasting model is designed by [43] which is used to reduce the power consumption overhead by using WSN. The authors [26, 43] had proposed the WSN based solution for flood forecasting.

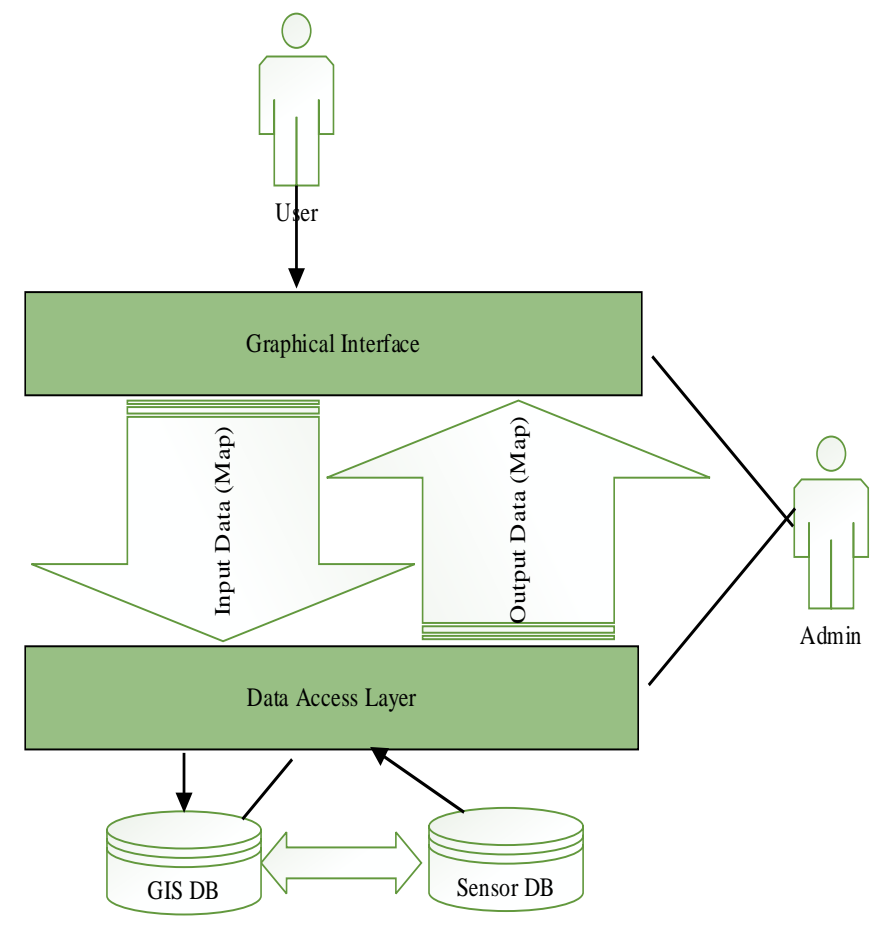

Fig. 7. Deployment of WSN with GIS Scenario. 


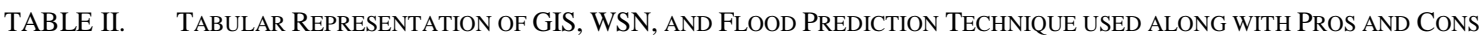

\begin{tabular}{|c|c|c|c|c|}
\hline Paper Ref & $\begin{array}{l}\text { WSN and GIS-based Flood } \\
\text { Forecasting schemes }\end{array}$ & Frameworks/Models discussed & Strengths & Limitations \\
\hline [1] & $\begin{array}{l}\text { Flood Prediction Model for Fuzzy } \\
\text { Logic has been discussed }\end{array}$ & $\begin{array}{l}\text { Flood Risk Model is designed for } \\
\text { a Probability distribution }\end{array}$ & $\begin{array}{l}\text { Flood Risk probability is calculated } \\
\text { in a specific region }\end{array}$ & $\begin{array}{l}\text { Mathematical Model is } \\
\text { complex }\end{array}$ \\
\hline [2] & $\begin{array}{l}\text { Probabilistic Model for Flood } \\
\text { forecasting has been designed }\end{array}$ & $\begin{array}{l}\text { Weather forecasting is based on } \\
\text { Distributed Systems }\end{array}$ & $\begin{array}{l}\text { Peak discharge ratio is calculated by } \\
\text { using a Metrological data set } \\
\text { (COSMO) }\end{array}$ & $\begin{array}{l}\text { Test duration period is } \\
\text { relatively short, Seventeen } \\
\text { months }\end{array}$ \\
\hline [5] & $\begin{array}{l}\text { Runoff Process and peak-flow } \\
\text { discharge process is numerically } \\
\text { calculated }\end{array}$ & $\begin{array}{l}\text { hydrological models are used to } \\
\text { predict flash flood events }\end{array}$ & $\begin{array}{l}\text { Temporal rainfall process and } \\
\text { spatial resolution is used to } \\
\text { calculate flood runoff process }\end{array}$ & $\begin{array}{l}\text { Complex Framework Model } \\
\text { is designed }\end{array}$ \\
\hline [10] & $\begin{array}{l}\text { ANN-based rainfall-runoff Model has } \\
\text { been designed }\end{array}$ & $\begin{array}{l}\text { System Model has been designed } \\
\text { based on input, output and hidden } \\
\text { layer }\end{array}$ & $\begin{array}{l}\text { Input parameters for flood } \\
\text { forecasting have been designed }\end{array}$ & $\begin{array}{l}\text { Simulation results are not } \\
\text { obtained }\end{array}$ \\
\hline [17] & $\begin{array}{l}\text { WSN based Flood Forecasting } \\
\text { Model has been designed }\end{array}$ & $\begin{array}{l}\text { Flash Flood events are predicted } \\
\text { based on the Statistical Model }\end{array}$ & $\begin{array}{l}\text { Graphical results are based on } \\
\text { instantaneous water levels }\end{array}$ & $\begin{array}{l}\text { Node deployment scheme is } \\
\text { based on Hybrid WSN }\end{array}$ \\
\hline [26] & $\begin{array}{l}\text { Monitoring for early warning Flood } \\
\text { system based on WSN }\end{array}$ & $\begin{array}{l}\text { Flood prediction Algorithm is } \\
\text { designed }\end{array}$ & $\begin{array}{l}\text { An algorithm is implemented in Mat } \\
\text { lab }\end{array}$ & $\begin{array}{l}\text { Difficult to implement in a } \\
\text { real-life scenario }\end{array}$ \\
\hline [28] & $\begin{array}{l}\text { Ensemble Prediction System (EPS) is } \\
\text { based on Flash Flood Forecasting }\end{array}$ & $\begin{array}{l}\text { Hydrological Modeling } \\
\text { (deterministic prediction) } \\
\text { technique has been used }\end{array}$ & $\begin{array}{l}\text { Numerical weather prediction is } \\
\text { used for Flood warning situations }\end{array}$ & $\begin{array}{l}\text { un certainty in future rainfall } \\
\text { Modeling has been identified }\end{array}$ \\
\hline [30] & $\begin{array}{l}\text { Bayesian Flood Forecasting systems } \\
\text { (BFS) has been designed }\end{array}$ & $\begin{array}{l}\text { The stochastic distribution Model } \\
\text { is designed for the prediction of } \\
\text { Flash Flood disasters. }\end{array}$ & $\begin{array}{l}\text { predictive distribution scheme is } \\
\text { used for accurate calibration }\end{array}$ & $\begin{array}{l}\text { Flood Forecast Model } \\
\text { generated uncertain results }\end{array}$ \\
\hline [31] & $\begin{array}{l}\text { Flood assessment is Scheme is based } \\
\text { on GIS-based WSN }\end{array}$ & $\begin{array}{l}\text { Mathematical Model is designed } \\
\text { for calculating Flood series } \\
\text { frequency }\end{array}$ & $\begin{array}{l}\text { Flood estimation methodology has } \\
\text { been designed }\end{array}$ & $\begin{array}{l}\text { Environmental parameters } \\
\text { are nor identified properly for } \\
\text { Flash Flood Forecasting. }\end{array}$ \\
\hline [35] & $\begin{array}{l}\text { Dynamics of a drainage system is } \\
\text { based on Sewer System Simulation }\end{array}$ & $\begin{array}{l}\text { Conceptual Model in case of Flood } \\
\text { foresting is designed for Urban } \\
\text { areas }\end{array}$ & $\begin{array}{l}\text { Rain Fall and Runoff Analysis for a } \\
\text { hundred-year storm has been } \\
\text { calculated }\end{array}$ & $\begin{array}{l}\text { Statistical Framework has not } \\
\text { been designed }\end{array}$ \\
\hline [43] & $\begin{array}{l}\text { WSN based Algorithm is designed for } \\
\text { flood forecasting }\end{array}$ & $\begin{array}{l}\text { The flood forecasting model is } \\
\text { based on linear regression }\end{array}$ & $\begin{array}{l}\text { Mathematical Model is designed to } \\
\text { reduce power consumption } \\
\text { overhead }\end{array}$ & $\begin{array}{l}\text { Percentage error is obtained } \\
\text { based on the predicted water } \\
\text { level }\end{array}$ \\
\hline
\end{tabular}

\section{Problem Statement And Research Questions}

Flood forecasting schemes using ANN require extensive computations, a large amount of data for training, large storage, and high processing capabilities. The numbers of input parameters are fixed for different regions that make it a rigid one. The major limitation of the existing research is that the river basin and other water reservoirs towards the dam or barrage are considered static entities. The impact of environmental parameters on flood prediction is based on existing readings taken from the old infrastructure of water reservoirs and rivers etc. The number of river basins and canals towards the dam may change over the passage of time and new entities can be added in the existing infrastructure. It can vary the flow, speed, storage, and level of water entering in the dams. Due to these dynamic parameters, the accuracy of flood prediction is highly reduced and even can produce false results. System reliability reduces as there are no redundancy checks to identify and correct the false calculations. The resultant values calculated based on false or out of bound environmental parametric values can generate wrong results. It could be much worst to produce opposite results in case negative values are generated instead of positive ones. These false results can be further saved in a database for future calculations for flood prediction. These false calibrations may result in inaccurate predictions which may cause extreme damage.
The following are the research questions that will be solved during this work:

1) How to design a Flood Forecasting Model by using GIS-based Wireless Sensor Networks?

2) How to collect the Flood Forecasting input Parameters by using Ad-hoc wireless Sensor architecture.

3) To design a Mathematical Model for Flood Forecasting by using Polynomial based approximation.

4) To generate the results of the Flood Forecasting technique by plotting graphs and pie charts.

5) Finally, perform the comparative analysis of the Actual and predicted Results.

The significance of the proposed research study is based on the critical evaluation of the literature studied during this research. This research study investigates how to build standard rules and regulations to be followed by developing nations in case of any flood emergency circumstance. The core issue for the research mainly depends upon the classification of determining flood level duration which directly affects the STRUCTURE of the buildings in the residential area. Almost the majority of Authors had discussed the applications of GIS, ANN, and WSN in flood event circumstances, but some of the Authors had proposed that using special-purpose sensors and hydrology based parameters plays a significant role in flood risk assessment and adopting precautionary measurements. The 
Remote sensing approach can also be adopted for the potential impact of flood risk depending on the specified geographical region. This work will be effective in managing the water level in dams and open the spillways for small intervals of time as per the actual picture of input water to either avoid flood situations or keep the water level to a lower value in flood. It will also help in analyzing the water levels and environmental parameters to predict the flood before time. It will save or reduce the damage in rural and agricultural areas in terms of crops, livestock, human lives, and house holdings, etc.

\section{PROPOSED SOLUTION}

This section presents an improved Flood warning system based on different parameters by using WSN and Artificial Neural Networks. Improvements in the low powered tiny sensor nodes working in Ad hoc infrastructure is one of the key factors in this research work. WSN used in flood forecasting is based on the efficient utilization of sensor nodes based on different clustering schemes. The proposed system consists of multiple wireless sensor nodes organized in a cluster group hierarchy deployed near to the river bed. The collector node is responsible for reading the flood characteristics from multiple sensor nodes. The collector node is also responsible for processing capability based on ANN-based polynomial approximation. In the system model, different nodes are involved to perform mandatory duties to fulfill the flood prediction scenario using WSN. Fig. 8 provides detailed information about the framework related to the proposed solution. The proposed framework consists of three clusters working in Flood forecasting and disaster risk assessment. Each cluster within the network consists of a collector node surrounded by multiple sensor nodes. The sensor nodes are responsible to transfer the disaster information to the collector node. The collector nodes within each cluster are capable to communicate with each other using Ad hoc wireless infrastructure. Each collector node is also capable to transmit the disaster-related information to the administration unit. The Administration Unit is finally responsible to update disaster information in its online database management system.

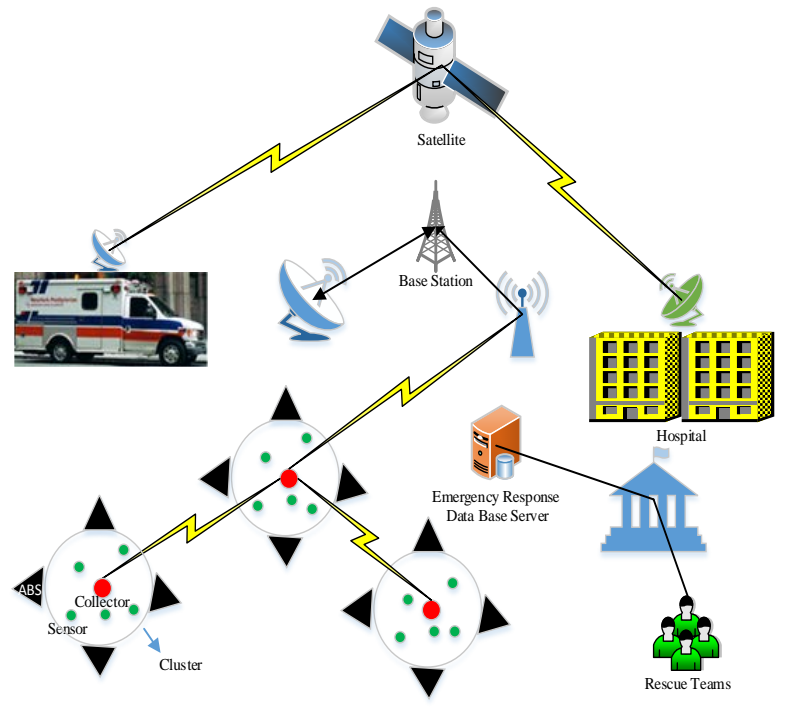

Fig. 8. Proposed Framework for Flood Forecasting.
The main responsibility of a sensor node is to sense the data from the surrounding and store in flash memory. The sensor can also GENERATE an alert when sensor readings are higher than the threshold values. The sensor can identify the query request and can send a reply to the collector node as per query requirements. These nodes are responsible to transmit the alarming messages to the AU. Moreover, $\mathrm{CN}$ can also collect the data in response to query from all nodes to transmit towards neighboring CNs that forwards towards the AU. The administrative activities and threshold values sent by AU are also coordinated via $\mathrm{CN}$ to sensor nodes. The Administration Unit is responsible to collect the disaster-related information (Flood forecasting parameters) from the collector nodes. The Administration unit has strong processing capabilities. The administration unit is capable to store the Flood forecasting parameters in its database. The Flood prediction Algorithm has been deployed on the Administration unit. In this research study, the most appropriate flood prediction technique has been used and also design its mathematical model using polynomial based approximation and artificial neural networks. The flood prediction input parameters would be very helpful for us in estimating the rate of flood occurrence.

During the applicability of the proposed solution, the following assumptions have been considered;

- An intrusion detection system should be implemented in a server at the Administration Unit (AU).

- AU should be capable of performing extensive parameter calculations regarding flood prediction.

- The sensor node should be able to keep a record of temperature, humidity, velocity, etc. It should also be able to generate alerts when the threshold value is crossed.

- Collector Node (CN) which is a sensor device should have sufficient resources in terms of energy, computation, and communication powers.

- CN should be able to collect, aggregate, and compress the water, rainfall, etc. data from member nodes.

- The power consumption factor in the case of wireless sensor nodes working in sleep mode should be reduced to a great extent.

Each deployed sensor node is a battery-powered device. The WSN consists of even hundreds or thousands of sensor nodes. The major constraints in WSN are based on communication bandwidth related to the sender node and receiver node. Sensor nodes are limited to battery-powered devices. In a multi-hop environment, a sensor node can act as a sender and as well as the receiver node. The major objective of this research related to the communication cost is dependent on using a limited size of data. This data can easily be transferred from the transmitter node to the receiver node to reduce the communication overhead. The storage unit in the wireless sensor node plays a very important role in data collection and aggregation. The size of data should be limited enough to be easily stored in the wireless sensor node. Sensor nodes can use the limited amount of energy in performing computations and transmissions. The sensor node consists of a sensing unit, 
processing unit, and the transmission unit. Energy-efficient routing protocols also plays a strong role in data transmission and aggregation. The energy consumption factor is measured during the information exchange of flood-related parameters. WSN is capable enough to transfer the Flood forecasting information safely in a minimum period from the transmitter node to the receiver node. The time analysis is performed for transferring the information from the sensor to AU. The input parameters used for the WSN simulation are water velocity, water level, Air moisture, wind velocity, rainfall, and Atmospheric pressure. The resulting values are checked from sensors by comparing them with saved Boundary values of different water resources.

\section{RESUlTS AND DisCUSSION}

The flood forecasting techniques are based on artificial neural networks (ANN), Particle swarm optimization (PSO), Regression-based technique, Fuzzy logic, and Time-series data mining. The SIMULATION scenario is created by using a network simulator (NS 2). The simulation results are collected by using ARC GIS simulation tools. The simulation of flood forecasting mathematical equations are used by using ANNbased polynomial approximation. The performance evaluation of simulated results has been identified. Arc GIS is a desktopbased application specially designed for working with maps based on geographic information. ARC GIS tool is capable to create the layered maps based on spatial data [22]. Network Simulator is an open-source simulation tool. Simulation of wireless and wired networks including routing algorithms TCP and UDP are implemented by using network simulator tools. NS 2 is based on $\mathrm{C}++$ and Tool command language (TCL). It creates a trace file that stores the activities and events generated by devices under simulation. Finally, the results are extracted from the values printed in the trace file. The actual flood classification has been obtained from discharges at important river sites. The Analysis of actual flow depends upon actual inflow and outflow depending on reservoir designed capacity. The Real-time rainfall data set is very much helpful for us in identifying the flood forecasting parameters which include the intensity of rainfall in $\mathrm{mm}$, temperature, air pressure, humidity along with wind speed. For this reason, the Ad hoc Wireless Sensor Network Architecture has chosen as a Model to collect flood forecasting parameters via Ad hoc wireless sensor Nodes.

The simulation results have been obtained by using a Linear regression model via using the sklearn library. Spyder version 3.3.6 (Scientific Python Development Environment) has been used to generate Flood Prediction results via using Anaconda Navigator. The structure of results is based on training and testing data sets in green and blue color. Fig. 9 Xaxis represents the values that represent the number of months and along Y-axis are Flood prediction accuracy. Positive values represent the true positive and False positive values and negative values represent False-negative and true Negative values. The maximum convergence of positive training and testing values predicts the accuracy of the Prediction Model to Maximum extent.

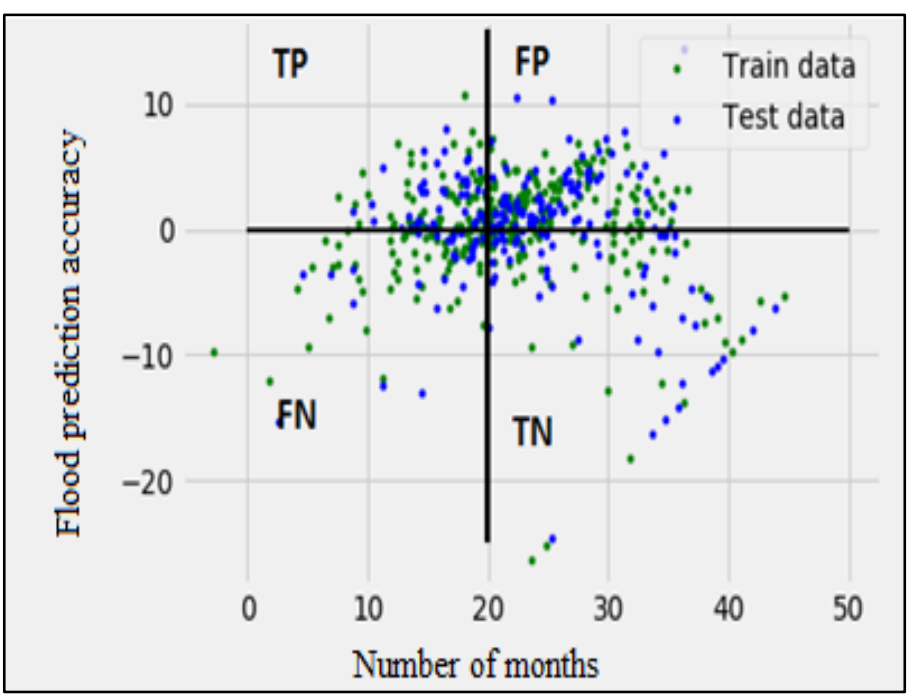

Fig. 9. Simulation Results for Flood Forecasting using Linear Regression.

The Accuracy (Classification rate) is obtained given by the following relationship:

Accuracy $=\frac{T P+T N}{T P+T N+F P+F N}$

The Recall is obtained given by the following relationship as mentioned as follows:

Recall $=\frac{T P}{T P+F N}$

The Recall is obtained given by the following relationship mentioned as follows:

Precision $=\frac{T P}{T P+F P}$

The F- measures are obtained given by the following relationship mentioned as follows:

$F-$ measure $=\frac{2 * \text { Recall } * \text { Precision }}{\text { Recall }+ \text { Precision }}$

\section{CONCLUSIONS AND FUTURE WORKS}

This research work investigates the development of the Flood Forecasting Model based on linear regression and confusion Matrix. The existing schemes have thoroughly studied to identify that the flood prediction solutions are rigid against the input parameters, infrastructure, and scalability. The existing solution becomes useless if there is a change in the surrounding like a new canal, stream, or dam is included in the system. The objective of this study is to generate the damage maps of the flood-affected areas by using remote sensing and social and infrastructure data sets. The core objective in this research study focuses on Remote Sensing which is an integral application of GIS and is used to create damage maps from social and infrastructure data sets in case of floods events. The Rainfall anomaly maps had also been used for peak water level analysis and compare the results with RADARSAT images for remote sensing. Along with RADARSAT images LANDSAT images have also been used for digitized image classification and comparison for flood monitoring and mapping. The proposed flood hazard model focuses on the Feed Forward Neural based approach in predicting the occurrence of Flood 
on a monthly and yearly basis. Based on the obtained results it is analyzed that accurately predicts the intensity of flood. The proposed model can also be implemented in the future via using Convolution Neural Networks by obtaining more accurate results.

\section{ACKNOWLEDGMENT}

This Project was funded by the Deanship of Scientific Research (DSR), at King Abdulaziz University, Jeddah, under grant no. 611-153-D1439. The authors, therefore, acknowledge with thanks DSR for technical and financial support.

\section{REFERENCES}

[1] L. Feng and G. Luo, "Practical Study on the Fuzzy Risk of Flood Disasters," Springer Journal. Acta Applicandae Mathematicae, vol. 106, no. 3, pp. 421-432, 2009.

[2] L. Alfieri, J. Thielen, and F. pappenberger, "Ensemble hydrometrological simulation for flash flood early detection," Elsevier Journal of Hydrology, pp. 143-153, 2012.

[3] S. Tahir, S. T. Bakhsh, M. F. Abulkhair, and M. O. Alassafi, "An energyefficient fog-to-cloud Internet of Medical Things architecture," International Journal of Distributed Sensor Networks, vol. 15, pp. 1-13, 2019.

[4] P. A.A and B. U.U, "Flood detection system using wireless sensor networks," International Journal of Advanced Research in computer science and software Engineering, vol. 5, no. 2, 2015.

[5] R. S, M. M and Y. Y, "Flash Flood Prediction using an uncelebrated hydrological model and radar rainfall data in a Mediterranean watershed under changing hydrological conditions," Journal of Hydrology, vol. 394, pp. 245-255, 2010.

[6] A. N, H. M and R. N, "Adhoc wireless sensor Network Architecture for Disaster Survivor detection," International Journal of Advance Science and Technology, vol. 34, 2011.

[7] M. Imran, S. T. Bakhsh, S. Tahir, M. Basheri, and M. Shoaib, "A reconfigurable scatternet formation and maintenance scheme with heterogeneous services for smart Bluetooth devices," Sustainable Cities and Society, vol. 40, pp. 589-599, 2018.

[8] Wang and Wen-Chuan, "A comparison of performance of several artificial intelligence methods for forecasting monthly discharge time series," Journal of hydrology, vol. 374, no. 3, pp. 294-306, 2009.

[9] G. Yasser and M. A. Serhani, "A WSN-driven service discovery technique for disaster recovery using mobile ad hoc networks," Wireless Days (WD), IFIP. IEEE, 2011.

[10] J. K. Roy, D. Gupta, and S. Goswami, "An improved flood warning system using WSN and Artificial Neural Network," India Conference (INDICON), 2012 Annual IEEE, 2012.

[11] S. Kar, A. D. Sarkar and N. Mukherjee, "An Integrated Framework in Geographic Information System using Wireless Sensor Network," International Journal of Computer Applications, 2012.

[12] Argany, Meysam, M. A. Mostafavi, F. Karimipour and C. Gagné, "A GIS based wireless sensor network coverage estimation and optimization: A Voronoi approach," In Transactions on Computational Science XIV, pp. 151-172, 2011.

[13] M. Abdullah, "Simulation of Wireless Sensor Network for Flood Monitoring System," Design, User Experience, and Usability. User Experience Design for Everyday Life Applications and Services. Springer International Publishing, pp. 255-264, 2014.

[14] E.A.Basha, S.Ravela and D.Rus, "Model based Mentoring for early warning Flood Detection," Proceedings of the 6th ACM conference on Embedded network sensor systems, vol. 5, no. 7, pp. 295-308, Nov 2008.

[15] J. Y. Z. X. H. B. Zhang Hailin, "GIS-based Risk Assessment for Regional Flood Disaster," IEEE International Conference on Environmental Science and Information Application Technology, 2010.

[16] S.Rozali, E.Morin, Y.Yair and C.Price, "Flash Flood Prediction using an uncelebrated hydrological model and radar rainfall data in a Mediterranean watershed under changing hydrological conditions," Elsevier Journal of Hydrology, vol. 394, pp. 245-255, 2010.
[17] V.Seal, A.Raha, S.Maity, S.Mitra, A.Mukrjee and M.K.Naskar, "A Real Time Multivariate robust Regression Based Flood Prediction Model using Polynomial Approximation for wireless sensor network based flood forcasting system," Springer Journal of Advances in Computer science and information Technology, vol. 86, pp. 432-441, 2012.

[18] Y. M. Xiaomeng, L. Xiaojuan, L. Y. Sun and X. Li, "Rapid Assessment of Flood Disaster Loss in Sind and Punjab Province, Pakistan Based on RS and GIS," IEEE Trans. (ICMT) International Conference on Multimedia Technology, pp. 646-649, July 2011.

[19] R. A, M. S, S. K. Mitra, J. R and M. K. Naskar, "A Low Complexity Multivariate Regression Based Flood Forecasting Model Using an Optimized WSN Deployment Scheme," Advanced Materials Research, vol. 403, pp. 3484-3494.

[20] Aziz, N. A. Ab and K. A. Aziz, "Managing disaster with wireless sensor networks," Advanced Communication Technology (ICACT), 2011 13th International Conference on. IEEE, 2011.

[21] Chen, Jian, A. A, Hill and L. D. Urbano, "A GIS-based model for urban flood inundation," Journal of Hydrology, vol. 1, no. 373, pp. 184-192, 2009.

[22] M. N.Ahmad, "Flood Prediction and Disaster Risk Analysis Using GIS based wireless sensor Networks," Journal of Basic and Applied Scientific Research, vol. 3, no. 8, pp. 632-643, 2013.

[23] " National Disaster Management Authority".

[24] X. Chen, X. Lu, Z. Liu, S. Fang, D. Jin, and L. Zeng, "A Heterogeneous High Speed Wireless Body Sensor Network Based on SC-UWB and ZIGBEE," IEEEGlobal Telecommunications Conference (GLOBECOM 2011), pp. 1-5, 2011.

[25] S. M. J. S. Samarasinghea, H. K. Nandalalb, D. P. Weliwitiyac, J. S. M. Fowzed, M. K. Hazarikad and L. Samarakoond, "Application of Remote Sensing and GIS for flood Risk Analysis:A Case study at Kalu-Ganga River SriLanka," International Archives of the Photogrammetry, Remote Sensing and Spatial Information Science, p. 101-109, 2010.

[26] S. M. J. S. Samarasinghea, H. K. Nandalalb, D. P. Weliwitiyac, J. S. M. Fowzed, M. K. Hazarikad, and L. Samarakoond, "GIS-based Risk Assessment Model for Flood Disaster in China," IEEE Trans. 18th International Conference on Geoinformatics, vol. 18, no. 20, pp. 1-5, June 2010.

[27] S. M. J. S. Samarasinghea, H. K. Nandalalb, D. P. Weliwitiyac, J. S. M. Fowzed, M. K. Hazarikad and L. Samarakoond, "Adaptive space-time sampling with wireless sensor nodes for flood forecasting," Journal of Hydrology, vol. 414, pp. 136-147, 2012.

[28] H. L. Cloke and F. Pappenberger, "Ensemble flood forecasting: A review," Elsevier Journal of Hydrology, vol. 375, pp. 613-626, September 2009.

[29] Y. Chen, W. Shen, HongweiHuo and Y. Xu, " A Smart Gateway for Health Care System Using Wireless Sensor Network," IEEE Trans. Fourth International Conference on Sensor Technologies and Applications (SENSORCOMM), vol. 18, no. 25, p. 545 - 550, 2010.

[30] B. Biondi and D. L. D. Luca, "Performance assessment of a Bayesian Forecasting System (BFS) for real time flood forcasting," Elsevier Journal of Hydrology, vol. 479, pp. 51-63, 2013.

[31] G. M. Dawood, M. N, M. Khalid, and A. A. Ghamdi, "GIS-Based Spatial Mapping of Flash Flood Hazard in MakkahCity, Suadi Arabia," Journal of Geograhic Information System, vol. 3, pp. 225-231, 2011.

[32] S. T. Bakhsh, R. AlGhamdi, A. H. Altalhi, S. Tahir, and M. A. Sheikh, "Adaptive Sleep Efficient Hybrid Medium Access Control algorithm for next-generation wireless sensor networks," EURASIP Journal on Wireless Communications and Networking, vol. 2017, pp. 84-94, 2017.

[33] M. A. Saud, "Assesment of Flood Hazard of Jeddah Area 2009, Suadi Arabia," Journal of Water Resource and Protection, pp. 839-847, 2010.

[34] J. Zhang, L. Song, F. Feng, and H. Gong, "Hydrologic Information Extraction for Flood Disaster Risk Assessment in Pearl River Basin and Luan River Basin, China," IEEE Trans. International Conference on geoinformatics, pp. 1-4, 2010.

[35] J. Chen, A. A, Hill, L. D and Urbano, "A GIS-based model for urban flood inundation," Elsevier Journal of Hydrology, pp. 184-192, 2009.

[36] J. Liu, J. Wen, K. Yang, Z. Shang and H. Zhang, "GIS-Based Analysis of Flood Disaster Risk in LECZ of China and Population Exposure," IEEE 
Trans. 19th International Conference on Geo informatics, Shanghai, China, 2011.

[37] H. Zhuowei, L. Xiaojuan, S. Yonghua, and Z. Liying, "Flood Disaster Response and Decision-making Support System Based On Remote Sensing and GIS," Flood Disaster Response and Decision-making Support System Based On Remote Sensing and GIS, pp. 2435-2438, 2007.

[38] S. Tahir, S. T. Bakhsh, R. Alghamdi, and M. Abulkhair, "Fog-based healthcare architecture for wearable body area network," Journal of Medical Imaging and Health Informatics, vol. 7, no. 6, pp. 1409-1418, 2017.

[39] N. Sulaiman, F. Husain, K. A. Hashim, and A. M. Samad, "A Study on Flood Risk Assessment for Bandar Segamat Sustainability Using Remote Sensing and GIS Approach," IEEE Control and System Graduate Research Colloquium (ICSGRC 2012), pp. 386-391, 2012.
[40] R. Jeberson, R. Raj and T. Sasipraba, "Disaster Management System based on GIS Web Services," IEEE Trans. Recent Advances in Space Technology Services and Climate Change (RSTSCC), p. 252 - 261, 2010.

[41] S. T. Bakhsh, R. A. A. AlGhamdi, A. H. Altalhi, S. Tahir, and M. A. Sheikh, "Adaptive Sleep Efficient Hybrid Medium Access Control algorithm for next-generation wireless sensor networks," EURASIP J. Wireless Comm. and Networking, vol. 2017, p. 1-15, 2017.

[42] C. Nie, H. Li, L. Yang, S. Wu, Y. Liu and Y. Liao, "Spatial and temporal changes in flooding and the affecting factors in China," Springer Journal of Natural Hazards, vol. 31, pp. 425-439, 2012.

[43] S. V, R. A, M. S, M. S. K, M. A, and N. M. K, "A simple flood forecasting scheme using wireless sensor networks," arXiv preprint arXiv:1203.2511, 2012. 